\title{
Sustaining Educational Equity: Architecture Development Programs as Transformative Models to Increase Inclusivity
}

\author{
LAUREN MATCHISON \\ University of Southern California
}

The desire to increase inclusivity in the field of architecture is concurrent with a perceptible growing trend in the United States in which many institutions of higher education have begun to take a closer look at student enrollment in the realization that various degree programs, including architecture, have historically lacked representation from people of color. Emerging architecture pipeline programs are poised to erode the demographic status quo by creating opportunities to engage historically underrepresented students while they are still in high school. Many of the explicit and implicit competencies these programs impart are valuable additions toward increasing the likelihood of more underrepresented students successfully applying to study architecture at the university level. These programs are only a small part of a growing number of efforts intended to address long-standing inequities in architecture education. This paper aims to assess such programs in light of Sharon Sutton's imperative to achieve and sustain educational equity set forth in her recent book, When Ivory Towers Were Black: A Story About Race in America's Cities and Universities. This paper first briefly identifies numerous diversity, equity, and inclusion initiatives currently taking hold in the discipline and profession of architecture. Next, it carefully examines Sutton's account of the Columbia University School of Architecture's attempt to transform the demographic status quo. Lastly, it considers the lessons learned from the experiment and applies them to emerging pipeline programs, referred to here as Architecture Development Programs, ultimately seeking to explore successful methods to attract, educate, and support historically underrepresented young people in the classroom and the profession.

\section{INTRODUCTION}

Attracting and retaining a more inclusive student body has become a top priority for architecture programs at universities nationwide. This is a relatively recent development that reflects a significant shift in larger cultural and organizational values. Many institutions of architecture education are no longer satisfied with the status quo; the status quo being that the discipline and practice of architecture is for the most part, devoid of people of color. Recent data from the American Institute of Architects confirms a widespread lack of inclusivity in the profession: a mere $3 \%$ of licensed architects in the United States are Latino, and less than $2 \%$ are Black. Data from educational surveys are not much more encouraging: approximately $18 \%$ of total student enrollment in architecture programs across the nation are Hispanic/Latino, while 5\% are African American. ${ }^{1}$ Acknowledgment of these bleak statistics has led, in part, to consensus that the status quo is no longer acceptable because it does not reflect the society in which we live, learn, and practice. Desire to dismantle the status quo is concurrent with a perceptible growing trend in the United States in which many institutions of higher education have begun to take a closer look at student enrollment in the realization that various degree programs, including architecture, have historically lacked representation from people of color.

Strategies to address underrepresentation in the profession have been in existence for some time, perhaps most notably during the racially charged 1960s and early 70s at Columbia University's School of Architecture. In her 2017 book, When Ivory Towers Were Black: A Story About Race In America's Cities and Universities, Sharon Egretta Sutton, PhD, FAIA, chronicles the shifting policies and priorities during the "experiment" as she calls it, in which a cohort of historically underrepresented people, including herself, earned degrees from Columbia's School of Architecture. Sutton's book explains that ultimately, the experiment at Columbia could not be sustained, and the demographic status quo returned within a few years. However, Sutton's text transcends a precise recount of the context of the experiment to consider how and why it failed. In retrospect, Sutton urges the reader to consider what a truly sustainable transformation might look like, and to discover the vital role that students, faculty members, and universities play in that process.

In light of Sutton's imperative to achieve and sustain educational equity, this paper aims to assess university pipeline programs created for high school students, programs that attempt to diversify architecture education, and thus, the profession. This paper first briefly identifies numerous diversity, equity, and inclusion initiatives currently taking hold in the discipline and profession of architecture. Next, it carefully examines Columbia's attempt to transform the demographic status quo. Lastly, it considers the lessons learned from the experiment and applies them to emerging pipeline programs, referred to here as Architecture Development Programs, ultimately seeking to explore successful methods to attract, educate, and support historically underrepresented young people in the classroom and the profession. 


\section{PERCEPTIBLE GROWING TREND}

The emerging view, that diversity benefits us all, is gaining momentum and is reflected on many fronts: within the task forces and resolutions of the American Institute of Architects (AIA), within the leadership committee and academic conferences of the Association of Collegiate Schools of Architecture (ACSA), in the ascendancy of student-focused groups like the National Organization of Minority Architecture Students (NOMAS) and local chapters of ACE Mentor Program of America. Not to mention the 2020 Conditions for Accreditation proposed by the National Architectural Accrediting Board (NAAB), which require that all programs seeking accreditation implement a formal policy on diversity and inclusion. ${ }^{2}$ Further, a general scan of recent scholarly journals, trade magazines, and architecture blogs alike cement the fact that interest in diversity, equity, and inclusion in architecture education has reached a critical mass.

To expand on this notion, consider the AIA: in 2015 it readily passed 'Resolution 15-1: Equity in Architecture' at the National Convention, which called for the creation of an Equity in Architecture Commission, whose purpose is to confront unbalanced demographics in the profession, understand root causes, and offer recommendations. Shortly after, the AIA released an Equity, Inclusion and Diversity Statement championing inclusion within the profession, declaring that achieving a vision of diversity will have a "direct impact on the relevance of our profession and the world's prosperity, health, and future."3

The professional community is not alone in its efforts to be more inclusive; its priorities are in lockstep with those of the educational community. As such, the charge given to the 2019-20 ACSA Leadership Committee relates directly to increasing access and promoting equity within the discipline of architecture. Specifically, the Leadership Committee has been charged with identifying strategies to increase access to architectural education and support retention for students from disadvantaged backgrounds to improve the racial, ethnic, socioeconomic, and gender diversity of schools and ultimately the profession. To further make good on this commitment, the 2019 ACSA conference at Stanford University, Less Talk More Action: Conscious Shifts in Architectural Education, featured a groundswell of educators emphasizing diversity, equity and inclusion (DEI) issues within university architecture degree programs nationwide. Conference speakers presented topics related to hidden barriers in the application process; the tacit expense of studio supplies, materials, field trips; inflexibility of studio hours to accommodate students with jobs, etc.

In an attempt to codify efforts like these, beginning in 2020 NAAB will require all degree programs seeking accreditation to have a diversity and inclusion plan in place. Section 5.5 of the Conditions for Accreditation necessitates that all programs describe their plan for increasing the diversity of its faculty, staff, and students. Programs must also explain methods for implementing the plan. ${ }^{4}$
Clearly, cries for meaningful change have now reached the ears of professional and educational organizations alike. Perhaps this is due in part to the abundance of personal narratives and imperatives that came before. Fifty years ago, civil rights leader Whitney M. Young Jr. admonished the AIA for its lack of diverse perspectives and the dearth of social and civic consciousness reflected in the work of its members. Young inspired and empowered others to speak out about the critical nature of expanding perspectives. Undoubtedly the most compelling and clear narrative, in this regard, belongs to Sharon Egretta Sutton, PhD, FAIA. Her recent book, When Ivory Towers Were Black: A Story About Race in America's Cities and Universities, published nearly half a century after Young's legendary speech, recounts her own story as a young black woman pursuing architecture in the turbulent 1960 s and 70s.

\section{SHARON SUTTON AND THE 'EXPERIMENT' AT COLUMBIA UNIVERSITY'S SCHOOL OF ARCHITECTURE}

Sutton's book chronicles the institutional transformation at Columbia University that began with a student-led rebellion in 1968, at the height of the Civil Rights movement. At the time, extreme racial tensions existed between Columbia and its adjacent neighborhood, Harlem. The outcome of the rebellion, which shut down the University for the summer, led in part to what Sutton describes as the "boldest recruitment effort among the country's architecture and urban planning schools." 5 The University's relationship with the Ford Foundation was critical in funding this effort to attract historically underrepresented students.

In her book, Sutton interrogates the recruitment effort and the resulting ethnic minority student enrollment between 1965-1976 and finds that "in a student body that ranged from about 300 to 350, the School of Architecture had a groundbreaking total of at least fifty-nine ethnic minority students in attendance during its evolutionary arc, including forty-nine who graduated." ${ }^{\prime 6}$ Sutton further points out that the number of graduating students peaked in 1973, with ten minority students graduating that year, and then declined to pre-existing levels after 1976, with a more typical 1 or 2 minority students graduating per year. ${ }^{7}$ Doing the math on Sutton's numbers puts the peak percentage of graduating ethnic minority students at Columbia's School of Architecture somewhere between $14-16 \%$ in the period between 1965-76. By comparison, 2018 NAAB data reveals that there were 5,995 accredited degrees awarded nationally in academic year 2017-18; 14\% (838) of those were awarded to Hispanic / Latino students, and 4\% (255) were awarded to Black / African American students. ${ }^{8}$ Today, the number of graduating underrepresented students is on par with or slightly better than Columbia's peak figure. However, considering that four decades have elapsed, it is shameful that today's figure is not demonstrably higher. 
This flat line of educational equity, or the status quo, as Sutton calls it, must be addressed and rectified. As Sutton asserts, even though the experiment was not sustainable, the transgressive nature of Columbia's recruitment effort was remarkably powerful, because "by embracing those who have been excluded from its privileges, the experiment demonstrated that transformation of the status quo, not charity, is diversity's undeniable benefit." 9

\section{SUTTON'S RECOMMENDATIONS FOR SUSTAINING EDUCATIONAL EQUITY}

Ultimately, Columbia "missed the boat," Sutton states, in that it was unable to make a sustainable commitment to attracting, supporting, and retaining underrepresented students. Accordingly, a sustainable commitment must be one that is forever. A sustainable commitment is not content merely with recruiting and matriculating underrepresented students, rather, it means supporting, mentoring, and tracking them once they have graduated. It means featuring graduates, hiring graduates, inviting graduates to mentor incoming students, to give talks, to participate in the circle of learning. A program with a sustainable commitment should actively and continually engage its alumni and encourage their involvement at multiple scales and points in time. Ultimately, to be sustainable, "the commitment must be a moral one, backed not only by financial resources, but intellectual resources..."10 If institutions are not willing to make such a commitment, the status quo will remain entrenched.

Logically, a sustainable commitment by an architecture program translates into more underrepresented people becoming professionals in architecture and the built environment. This is primarily because an institution committed to educational equity would not abandon alumni on the long and arduous post-graduation path to licensure, rather, it would provide continuous support and connectedness. Such a commitment fights attrition from the field of architecture, a fate more likely to effect black graduates than white graduates. ${ }^{11}$

Notably, graduates from Columbia's experiment experienced relatively low levels of attrition; the majority going on to become city-making professionals. Sutton theorizes that they overcame the odds for a few reasons: these students felt they belonged because they were part of a cohort; their education aligned with their worldview; they were able to make an impact in their own community through service-learning projects built in partnership with local groups. ${ }^{12}$ Columbia's ethnic minority cohort does not need to be an outlier in this regard. The favorable conditions Sutton describes are replicable and proven to be effective, in architecture and other disciplines.

Today, there is evidence that some institutions of higher education are willing to make a long-term commitment to achieving and maintaining educational equity. Some seem to have concurrently absorbed the lessons of the past and applied best practices of the present. Some seem to grasp the imperative to go beyond recruitment efforts alone and to create a culture of social bonding and shared vision. Some have finally discarded outdated and myopic traditions and begun to consider the entire ladder of educational and professional success. The remainder of this paper examines groundbreaking programs working toward these ends.

\section{TRANSGRESSIVE ACTION: THREE ARCHITECTURE DEVELOPMENT PROGRAMS HEED THE CALL}

In 2015 the American Institute of Architects surveyed its members, seeking data to better understand barriers to diversity in architecture and architecture school. 7,522 architects responded to the Diversity in the Profession of Architecture survey, identifying factors impacting the representation of minorities and strategies for addressing underrepresentation in the profession. One strategy recommended that university architecture programs increase outreach into middle and high schools. ${ }^{13}$

In retrospect, this strategy recommended by the AIA has already been acted upon in several schools of architecture that offer summer programs for high school students. These are clearly a step in the right direction, as recent research indicates that participation in college STEM summer bridge programs "double the odds that students plan to pursue a STEM career, compared with students without program exposure." ${ }^{14}$ Importantly, researchers found this to hold true across a range of demographics and student backgrounds.

Visionary leaders in three schools of architecture have begun to look beyond summer programs and to imagine a new type of experience, one that both realizes and amplifies the positive effects that STEM programs have on underrepresented young people. These Architecture Development Programs incorporate college-level architecture curricula into a typical high school semester that engages both the students and their parents or guardians, since data also suggest that parental involvement is critical in encouraging students of all backgrounds to consider careers in STEM fields. ${ }^{15}$

The first Architecture Development Program began at the University of Michigan's Taubman College of Architecture and Urban Planning in 2015. It was conceived by then dean, Mónica Ponce de León, and associate dean Milton S.F. Curry, as a way to expose and immerse high school juniors in the Detroit Public School system to architecture, urbanism, and integrated design practices. The program, called ArcPrep, is a one semester college-level architecture course with three modules: architecture studio, career exposure, and career counseling. Students earn high school credit for this course; they also gain invaluable help with preparing a portfolio and writing college admissions essays. ArcPrep meets three hours per day, five days per week over the course of one semester. The program is held off-campus in midtown Detroit and is taught by Michigan/Mellon Fellows, who hold graduate degrees in architecture. Now in its sixth year, ArcPrep has educated over 200 students. ${ }^{16}$ 
This revolutionary program, initiated in the Midwest, naturally expanded when Ponce de León and Curry both accepted deanships on the East coast and West coast, respectively. In 2016 Ponce de León left Michigan to become the dean of Princeton University's School of Architecture; Curry departed the following year to become dean of the University of Southern California's School of Architecture. In this way, Michigan's ArcPrep Program set the foundation and framework for the next two Architecture Development Programs: Princeton's ArcPrep Program, which launched in 2018, and USC's A-LAB Architecture Development Program, anticipated in 2021.

All three programs contain the same DNA. They share the same mission: to educate and support underrepresented students living in urban communities on their path to college, and empower them to become future leaders and designers. They share the same structure: a one-semester immersive experience for high school students; a commitment of approximately three hours per day, five days per week; a cohort of approximately 20 students per semester; an off-campus location; a project-based curriculum taught by Fellows. They share the same pedagogical emphases: issues-based studio; exposure to the profession and the culture of the profession; and college readiness. Importantly, all programs have mechanisms in place to mentor and engage students in the time after they complete the program and before they go to college. But perhaps what is equally important to the academic content is the sense of belonging that such programs can foster. Clearly, Sutton believes that a sense of belonging contributed to the Columbia students' willingness to become city-making professionals. Recent research confirms her insight and has begun to consider how a sense of belonging has become increasingly relevant to understanding how to improve college student success. ${ }^{17}$

\section{STAYING THE COURSE: HOW ARCHITECTURE DEVELOPMENT PROGRAMS BUILD COMMUNITY AND COMMITMENT}

This portion of the paper considers Sutton's position that a sense of belonging, shared vision, and community impact are important factors in attracting, retaining, and supporting historically underrepresented students and investigates whether Architecture Development Programs embrace such strategies.

Belonging is a basic human need. A sense of belonging is defined as a "sense of personal involvement in a social system so that persons feel themselves to be an indispensable and integral part of the system."18 Experts on higher education and education psychology like Darnell Cole cite a wide body of research affirming that a sense of belonging can significantly aid in breaking down barriers for college students from historically marginalized backgrounds. In a 2019 article in the journal American Behavioral Scientist, Cole et. al. synthesize research concluding that "most studies have found that students of color, in particular, report a lower sense of belonging in comparison with their White counterparts due to negative or challenging cultural and social experiences."19 In this light, building a culture of belonging seems critical to the success of students in an Architecture Development Program, or any program, for that matter.

Architecture Development Programs (ADP) get it right when they create small cohorts of students from one or more high schools who are linked by their interest in architecture and the built environment and their desire for academic success. Over the course of the semester, one can imagine that these students feel that they belong to each other, in the same way that college freshman studying architecture report feeling a sense of family or special closeness to their studio peers. ADP's also attempt to create a sense of belonging not only among the student cohort itself, but between the cohort and the host university. For example, high school students in Princeton's ArcPrep regularly visit Princeton's School of Architecture; they visit studio and meet with architecture students, they view exhibitions, they visit the Embodied Computation Lab and tour the School. Michigan's ArcPrep program strives for a similar level of connectedness between the program and the College. One project involves designing a full-scale chair: first students design and construct a prototype out of cardboard in the Michigan Research Studio in Detroit, then they travel to the College's Fabrication Lab in Ann Arbor to use the CNC machine to build it out of wood with assistance from faculty and undergraduate students. Notably, Michigan's ArcPrep program strives to keep the sense of belonging strong even after students complete the program by inviting ArcPrep alumni to return the following year in the role of critic. Program alum help with desk crits and project reviews for the new cohort of students, and in this way, further their connection to the program and other mentoring opportunities. Underlying the curriculum and inherent in the structure of the ArcPrep programs is the desire to combat social isolation by connecting students and creating a sense of familiarity, ease, and belonging to university campuses.

Along with cultivating a sense of belonging, Sutton speculates that a shared worldview also played a role in the Columbia cohort's lack of attrition. Sutton states that these students' education aligned with their worldview and was therefore able to address the inequities they grew up with. Lorelle Espinosa, expert in higher education, policy, and research, might refer to the ability to align education with worldview as creating a "culture of intentionality." Espinosa describes such a culture as one that, "meets students where they are when they arrive on campus, sets high expectations for student success, and tailors programs, services, and institutional policies to recognize and address students' academic, financial, and social needs-all with cultural mindfulness." ${ }^{20}$ The students participating in the Architecture Development Programs reside in Detroit, Trenton, and South Central Los Angeles; many grew up in predominantly low-income neighborhoods in urban regions and 
attend low-performing public schools. A culture of intentionality seems especially important to foster in the host university at large, in order to increase these students' likelihood of success. This cultural mindfulness aligns with other research recommending that "institutions must attend to both their formal and informal environments in order to facilitate a more tolerant and responsive racial and general campus climate."21

The third component of Sutton's assessment relates to community impact. The Columbia cohort felt they were able to positively impact their local community through servicelearning studio projects built in partnership with local groups. These students realized firsthand the ability of design to bring about meaningful change as they worked on real projects in Harlem, projects like a storefront community center, pocket parks, plans for an alternative high school, and a publication on tenant's rights. Service-learning at the time was a form of social activism, a way of supplementing classroom learning with direct neighborhood contact and seems to have resonated deeply with the cohort students. The socially oriented service-learning of the 1960 s serves as precursor to the issuesbased projects students confront in today's Architecture Development Programs. Both ArcPrep programs and USC's forthcoming A-LAB program recognize the value of designing local interventions so that students can imagine working and impacting their own community. (Although neither program refers to its studio projects as service-learning, preferring to stick to terms like social issues-driven and issues-based.) Regardless of nomenclature, a documented benefit to projects like these is that they are inherently collaborative and interdisciplinary. They engage many different building leaders - people like architects, landscape architects, planners, developers, artists, clients, and users - which exposes the students to a broader, more realistic, and more accessible view of the building process. For example, Michigan's ArcPrep program asks students to design a pavilion for an urban farm in Detroit, because they have found that small scale local projects involving multiple building actors helps the students quickly connect to a project. Each of the Architecture Development Program's curricula indicates a belief that projects should have an urban presence, and are more successful when they confront issues of consequence to students, ultimately showing students that they have agency in their own city.

\section{CONCLUSION}

As this brief overview indicates, Architecture Development Programs are poised to erode the demographic status quo by creating opportunities to engage historically underrepresented students while they are still in high school. Many of the explicit and implicit competencies these programs impart are valuable additions toward increasing the likelihood of more underrepresented students successfully applying to study architecture at the university level. The overall intent being that issues-based studio projects impart hard skills like drawing, model building, and software proficiency, as well as soft skills like collaboration, public speaking, interacting with professors, and an improved awareness of the built environment. These skills paired with an effective portfolio, improved college essays, and increased college readiness will ideally build confidence and capability in students and facilitate their acceptance into college.

These programs are only a small part of a growing number of efforts intended to address long-standing inequities in the discipline and profession of architecture, and they are too new to determine how effectively they help students transition to college. However, pipeline programs like these cannot transform the status quo on their own. Such programs must be buttressed by infrastructural and systemic change at the institutional level in order to achieve and sustain educational equity.

Emerging Architecture Development Programs are necessary and an important point of departure, but research indicates that an all-out culture change is required to support diverse student success. Sutton herself implores us to consider the entire ladder of educational equity, not just the pipeline. Clearly, many schools of architecture are adopting a new set of values, but without corresponding infrastructural re-imagining, sustainable change is unlikely. The barriers that exist for underrepresented students are complex, shaped by historical forces, and reinforced by a society that remains unequal. ${ }^{22}$ Real change will come only when inequities are examined along the whole range of educational trajectories of underrepresented students.

\section{ENDNOTES}

1. National Architectural Accreditation Board, 2018 Annual Report on Architectural Education, 11.

2. National Architectural Accreditation Board, 2020 Conditions for Accreditation, 12.

3. AIA Equity, Diversity and Inclusion Commission, Executive Summary 2017, 8

4. National Architectural Accreditation Board, 2020 Conditions for Accreditation, 12

5. Sharon E. Sutton, "When Ivory Towers Were Black: Lesson in Diversifying the City-Making Professions" Department of Architecture Winter 2018 Lecture Series (lecture, University of Washington, Seattle, WA, March 7, 2018)

6. Sharon E. Sutton, When Ivory Towers Were Black: A Story about Race in America's Cities and Universities (New York: Fordham University Press, 2017), 10-11.

7. Ibid, 11, figure 3 .

8. National Architectural Accreditation Board, 2018 Annual Report, 16

9. Sutton, "When Ivory Towers Were Black: Lesson in Diversifying the CityMaking Professions,"

10. Ibid

11. Stephen A. Kliment, "Diversity, What the Numbers Tell Us," AlArchitect, October 13, 2006. http://info.aia.org/aiarchitect/ thisweek06/1013/1013rc_face.pdf.

12. Sutton, "When Ivory Towers Were Black: Lesson in Diversifying the CityMaking Professions,"

13. American Institute of Architects, Diversity in the Profession of Architecture Executive Summary 2016.

14. Joseph A. Kitchen, Philip Sadler, and Gerhard Sonnert, "The Impact of Summer Bridge Programs on College Students' STEM Career Aspirations," Journal of College Student Development 59, no. 6, (November-December 2018) DOI: https://doi.org/10.1353/csd.2018.0066 
15. Christopher S. Rozek, Ryan C. Svoboda, Judith M. Harackiewicz, Chris S.Hulleman, and Janet S. Hyde, "Utility-value Intervention with Parents Increases Students' STEM Preparation and Career Pursuit," Proceedings of the National Academy of Sciences (Jan 2017) DOI:10.1073/pnas.1607386114

16. "Michigan Architecture Prep," Taubman College, University of Michigan, access November 1, 2019, https://taubmancollege.umich.edu/architecture/ high-school-programs/michigan-architecture-prep

17. Darnell Cole, Christopher B. Newman, and Liane I. Hypolite, "Sense of Belonging and Mattering Among Two Cohorts of First-Year Students Participating in a Comprehensive College Transition Program," American Behavioral Scientist, (2019), 3. DOI:10.1177/0002764219869417

18. Santohk S. Anant, "Belongingness and Mental Health: Some Research Findings," Acta Pyschologica, 26 (1967), 391.

19. Cole, Newman, and Hypolite, "Sense of Belonging and Mattering...," 3.

20. Lorelle Espinosa, foreword to "Creating a Diverse Student Success

Infrastructure: The Key to Catalyzing Cultural Change for Today's Student," by Adrianna Kezar, (Los Angeles: University of Southern California, Pullias Center for Higher Education, 2019), 1.

21. Dawn R. Johnson, Matthew Soldner, Jeannie Brown Leonard, Patty Alvarez, Karen Kurotsuchi Inkelas, Heather T. Rowan-Kenyon, Susan D. Longerbeam, "Examining Sense of Belonging Among First-Year Undergraduates From Different Racial/Ethnic Groups," Journal of College Student Development, Volume 48 Number 5 , (September/October 2007), 538. DOI: https://doi. org/10.1353/csd.2007.0054

22. Espinosa, foreword to "Creating a Diverse Student Success Infrastructure...," 1. 